\title{
Revealing glacier flow and surge dynamics from animated satellite image sequences: examples from the Karakoram
}

\author{
F. Paul \\ Department of Geography, University of Zurich, Zurich, Switzerland \\ Correspondence to: F. Paul (frank.paul@geo.uzh.ch)
}

Received: 20 February 2015 - Published in The Cryosphere Discuss.: 27 April 2015

Revised: 1 November 2015 - Accepted: 2 November 2015 - Published: 26 November 2015

\begin{abstract}
Although animated images are very popular on the internet, they have so far found only limited use for glaciological applications. With long time series of satellite images becoming increasingly available and glaciers being well recognized for their rapid changes and variable flow dynamics, animated sequences of multiple satellite images reveal glacier dynamics in a time-lapse mode, making the otherwise slow changes of glacier movement visible and understandable to the wider public. For this study, animated image sequences were created for four regions in the central Karakoram mountain range over a 25 -year time period (1990-2015) from freely available image quick-looks of orthorectified Landsat scenes. The animations play automatically in a web browser and reveal highly complex patterns of glacier flow and surge dynamics that are difficult to obtain by other methods. In contrast to other regions, surging glaciers in the Karakoram are often small $\left(10 \mathrm{~km}^{2}\right.$ or less $)$, steep, debris-free, and advance for several years to decades at relatively low annual rates (about $100 \mathrm{ma}^{-1}$ ). These characteristics overlap with those of non-surge-type glaciers, making a clear identification difficult. However, as in other regions, the surging glaciers in the central Karakoram also show sudden increases of flow velocity and mass waves travelling down glacier. The surges of individual glaciers are generally out of phase, indicating a limited climatic control on their dynamics. On the other hand, nearly all other glaciers in the region are either stable or slightly advancing, indicating balanced or even positive mass budgets over the past few decades.
\end{abstract}

\section{Introduction}

\subsection{Visualizing glacier dynamics}

Analysis of sequential satellite images has become a common tool for deriving glacier changes through time in all parts of the world. A "standard" way of documenting these changes in scientific journals is the overlay of glacier outlines from different points in time on one of the images used for the analysis (e.g. Baumann et al., 2009; Bhambri et al., 2013; Paul et al., 2004). In the case where multiple images are available and changes take place mostly at the glacier terminus (e.g. during an advance or retreat phase), terminus positions are indicated by multiple lines with years either attached to them (e.g. Jiskoot and Juhlin, 2009) or colourcoded (McNabb and Hock, 2014; Quincey et al., 2011; Rankl et al., 2014). When complex interactions take place between two glaciers (e.g. a tributary is merging with another glacier), phases of the changes are illustrated by showing sequential images side by side (e.g. Belò et al., 2008; Bhambri et al., 2013; Copland et al., 2011; Mukhopadhyay and Khan, 2014 ) or by two-dimensional drawings of changes in major moraine patterns (e.g. Hewitt, 2007; Meier and Post, 1969; Quincey et al., 2015).

Although these representations of changing glaciers are scientifically sound and exact, they have some limitations in demonstrating dynamic aspects. The key issue is related to the limited ability of the human brain to recognize differences between two (static) images when shown side by side or to translate various outlines of terminus positions into the correct sequence of changes, in particular when changes are out of phase for a couple of glaciers. On the other hand, the human brain recognizes movement well and tends to compensate missing parts in a sequence of animated images due 
to the slow processing of visual information, also known as the "phi phenomenon" (e.g. MacGillivray, 2007). This helps in translating time-lapse photography into continuous motion, thus making the dynamic nature of otherwise slowly moving objects or natural phenomena visible (e.g. cloud development, aurora, tides). While cameras with an interval timer were not common a decade ago and related footage was rare, today's widespread availability of webcams allows pictures to be taken remotely and automatically each day (or whatever period) at regular intervals. This can be particularly interesting when glaciers are imaged, as their movement is normally much too slow to be recognized (e.g. www.chasingice.com).

At the satellite scale, the application of "flicker" images (basically a rapid alternation of two images taken a few years apart) for demonstrating glacier changes is common practice and has been used to analyse glacier motion (Kääb et al., 2003). In this way, coherent patterns of displacement of the glacier surface have long been used to determine surface flow velocities from feature tracking using cross-correlation or other techniques (e.g. Kääb and Vollmer, 2000; Scambos et al., 1992; Paul et al., 2015). With the now free availability of long time series (starting in 1984) of orthorectified satellite imagery from Landsat (e.g. Wulder et al., 2012), it is possible to combine sequential satellite images into longer sequences ( $>20$ years) and demonstrate landscape changes in a time-lapse mode (e.g. world.time.com/timelapse2) including glacier flow and dynamic changes over large regions. This provides new insights and a more intuitive access to phenomena such as the mutual interaction of different glaciers, fast and slow flow of different glacier segments, advance and retreat patterns, downwasting (i.e. surface lowering without retreat), and the dynamics of supraglacial and proglacial lakes and river streams. Depending on the time step between the original images and the flow velocity of the glaciers, the impression of more or less continuous flow can be obtained by animating the individual images at high speed.

In this study animated sequences of orthorectified satellite images covering a 25-year time period (1990-2015) are used to demonstrate glacier dynamics and other landscape changes in four regions of the central Karakoram. Though this might be seen as a less quantitative approach than that of studies determining the exact rates of glacier change, the information obtained by looking at high-speed animations of the individual images also provides insight into dynamic glacier behaviour on a different level. There is also potential for using such animations for educational purposes by visualizing how glaciers flow and change through time. The animations use the very old ( $>25$ years) image format GIF, which has its drawbacks in terms of the number of colours that can be used (only 256), but it is the only format that allows a looping of high-frequency animations with screensize images. The format has recently become increasingly popular on the internet (e.g. giphy.com) and in mobile communication (Isaac, 2015) for short repetitive animations due to its easy use (no special software required) and relatively small file size.

\subsection{Surge-type glaciers}

The Karakoram mountain range has been selected due to its many surging glaciers that display a distinct dynamic behaviour (e.g. Copland et al., 2011; Gardelle et al., 2013; Hewitt, 2007; Rankl et al., 2014). According to Jiskoot (2011), a surge-type glacier oscillates between a period of slow or normal flow (lasting tens to hundreds of years) named the quiescent phase, and an active or surge phase during which flow velocities increase by a factor of 10-1000 over a short period (a few months to years), sometimes resulting in marked frontal advances (kilometre scale). During a surge, a large amount of ice is transported from a reservoir area to a receiving area where it melts after a surge, predominantly by downwasting. All three components (time periods for both phases, velocities, terminus advance) reportedly vary over a wide range (e.g. Sharp, 1988), resulting in an unclear separation from non-surge-type glaciers (cf. Table 5 in Sevestre and Benn, 2015) that might, for example, just advance over an extended period of time (Meier and Post, 1969). A surge-type glacier in its quiescent phase can often be identified from distortions of the normally parallel-aligned medial and/or lateral moraines (e.g. Grant et al., 2009; Kotlyakov et al., 2008). Such distortions may result from the speed-up of either a specific section of a glacier or the merging of a surging tributary with the main glacier (e.g. Hewitt, 2007). In the latter case it might be possible that the main glacier is - despite the surge marks on its surface - not of surge type.

While the Karakoram region is well known for its many surge-type glaciers (e.g. Copland et al., 2011; Hewitt, 2014), counting them is challenging as the frequently used criteria for their identification only partly apply. Many studies have thus introduced a "surge index" to indicate the certainty that a specific glacier is of surge type (cf. Sevestre and Benn, 2015). The evidence can be divided into geomorphological and dynamic categories (e.g. Jiskoot, 2011). The former include looped or distorted medial moraines, a glacier tongue that is largely covered by crevasses and séracs during a surge, a post-surge disconnection of the tongue well behind the terminus, and rapid downwasting after the surge with the formation of potholes and remaining stranded icebergs (e.g. Yde and Knudsen, 2005). Dynamic criteria include (among others) the terminus advance rate, the total advance over a given period, the duration of the advance and retreat (or quiescent) phase, the relative advance compared to the pre-advance glacier length, absolute values of surface velocity, significant velocity changes in specific regions of a glacier, surge periodicity and inverse thickness changes in the ablation (mass gain) and accumulation (mass loss) regions. For these dynamic criteria, the values for surging glaciers can be 1 to 3 orders of magnitude higher than for non-surge-type glaciers (e.g. Jiskoot, 2011). However, they can also lie within a simi- 
lar range, thus limiting the possibilities for a clear separation. For this study a glacier is called "surging" based on its easily identifiable strong and partly rapid advance or on the basis of its classification in previous studies (Copland et al., 2011; Gardelle et al., 2013; Rankl et al., 2014). In the event that other criteria are used (e.g. large changes in flow velocity), a different assignment might result.

\section{Study region, data sets and methods}

The study region is located in the central Karakoram mountain range (Fig. 1) to the north of - and including - the large and well-studied Baltoro Glacier (Quincey et al., 2009 and references therein). Four regions are selected for the animations: (1) Baltoro, (2) Panmah, (3) Skamri/Sarpo Laggo and (4) Shaksgam. All regions are well known for their many surge-type glaciers (cf. Copland et al., 2011; Rankl et al., 2014), several of which have been studied in more detail (Diolaiuti et al., 2003; Hewitt, 2007; Quincey et al., 2011; Rankl et al., 2014). The region is characterized by very steep and high terrain (often reaching more than $7000 \mathrm{~m}$ a.s.l.) with numerous multi-basin valley glaciers, that often have further tributary glaciers in their ablation zones (Iturrizaga, 2011). The anomalous glacier behaviour in the study region (mass gain and advancing glaciers over the past 2 decades), relative to most other regions of the world has been named the "Karakoram Anomaly" (e.g. Bolch et al., 2012; Hewitt, 2005). This behaviour might be attributable to an increase in precipitation (e.g. Janes and Bush, 2012), but the large number of actively surging glaciers in the region might also have non-climatic causes (e.g. Hewitt, 2005; Jiskoot, 2011). A recent study by Sevestre and Benn (2015) has suggested that glaciers in this region are located in the climatically "correct" zone for surge-type glaciers. Further details about the topo-climatic characteristics of the region can be found in Hewitt (2014).

The study region is completely covered by Landsat scene 148-35 (path-row) and partly by scene 149-35 (Fig. 1). Useful Landsat scenes (sensors TM, ETM+ and OLI) acquired near the end of the ablation period (summer) are available for 18 individual years since 1990 and four further scenes for the Panmah region from path-row 149-35 (see Table 1). For the animations provided in the supplemental material, only a selection of scenes have been used to limit file size and get similar temporal differences. The full set of individual scenes is provided on a separate web page (http://cryoportal.enveo. at/glaciers.html). A Landsat MSS scene (path-row: 160-35) from August 1977 was used to provide information on previous glacier extents, but is not integrated into the animations. Only the orthorectified quick-looks of all scenes were downloaded from earthexplorer.usgs.gov and used for the animations. They are provided as false colour composites at the original $30 \mathrm{~m}$ resolution, showing glaciers in light blue to cyan, clouds in white, water in dark blue, vegetation in

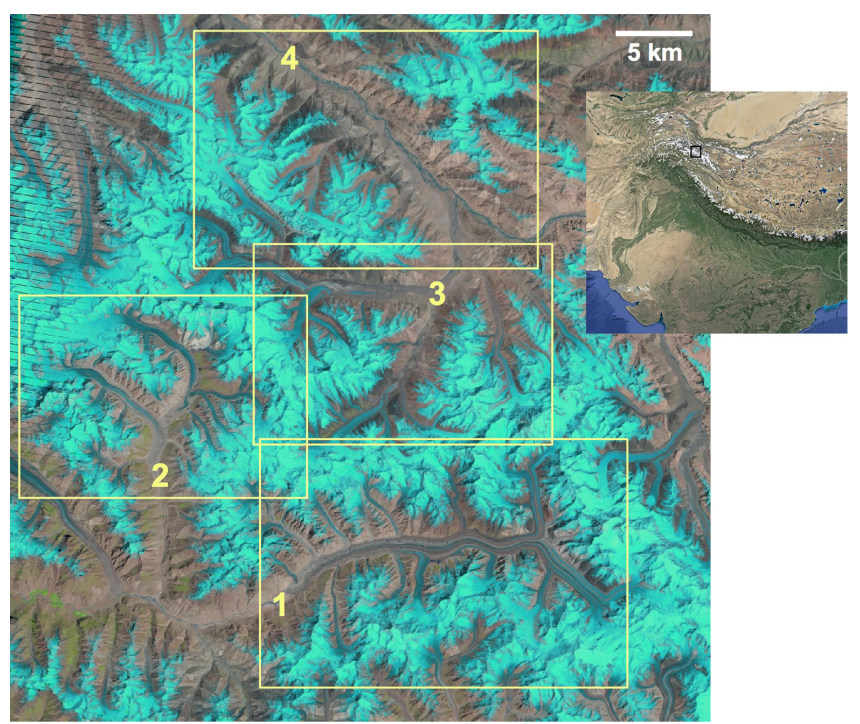

Figure 1. Landsat scene of the study region from 2004 showing footprints of the four subregions depicted in Figs. 2-5. The black square in the inset shows the location of the study region in the Karakoram mountain range (map taken from Google Earth). The image centre is at $36^{\circ} \mathrm{N}$, and $76.3^{\circ} \mathrm{E}$.

green and bare terrain in brown. All scenes are processed in a standardized processing line at USGS (with colours balanced) and are provided with extra files that include projection information and geolocation for easy import into GIS software.

The animations are created by displaying all images in a GIS (e.g. QGIS, ArcMap), exporting the maps to a 24-bit image file, converting all images to GIF format and by creating the animated GIF image with a delay of $1 / 10$ s using convert from ImageMagick. Annotated versions of the four subregions are shown in Figs. 2-5 for orientation and as a reference (using the scene from 2004). In general, the temporal difference between two images in the animation is 1 or 2 years (see Table 1), but sometimes it is also 3 or even more (e.g. 5 from 2004 to 2009).

\section{Observations in the study region}

A wide variety of dynamic changes are visible in the animations. They range from the variable extent of seasonal snow cover, to clouds (with their shadows) that pop up on individual frames, to the steady flow of large glaciers with traceable surface characteristics (moraines, lakes), to glacier fronts advancing and retreating at different rates, mass waves travelling through individual glaciers, downwasting of debris-covered glacier sections and short-term velocity pulses within a glacier. As all of the above are happening at the same time, it is easy to lose focus. Following the evolution of specific changes thus requires focussing the view on a specific region and ignoring everything else. In 
Table 1. Overview of the 21 Landsat scenes used to create the animations in the Supplement for the four subregions shown in Figs. $2-5$. The MSS scene is only added for completeness. Abbreviations are as follows. From the "sensor" column, MSS: MultiSpectral Scanner, TM: Thematic Mapper, ETM+: Enhanced Thematic Mapper + and OLI: Operational Land Imager. "Date" shows day.month, "day" signifies the day number within a year and "P-R" shows path-row. Letters in columns 7-11 denote the following subregions: $\mathrm{A}^{\prime}$ and A: Baltoro, B: Panmah, C: Skamri, D: Shaksgam. The number in each column, A to D, gives the order in the sequence. GLS: Global Land Survey. Note that for the animation in the Supplement, only the subset A is used; an extended time-series $\mathrm{A}^{\prime}$ can be created from the individual images available from http://cryoportal.enveo.at/glaciers.html.

\begin{tabular}{llllllllllll}
\hline No. & Sensor & Date & Year & Day & P-R & A $^{\prime}$ & A & B & C & D & Remarks \\
\hline 0 & MSS & 02.08 & 1977 & 214 & $160-035$ & - & - & - & - & - & not used for the animations \\
1 & TM & 07.08 & 1990 & 219 & $149-035$ & - & - & 1 & - & - & path 149 \\
2 & TM & 02.07 & 1991 & 183 & $148-035$ & 1 & 1 & - & - & - & \\
3 & TM & 19.08 & 1991 & 231 & $148-035$ & - & - & 2 & 1 & 1 & \\
4 & TM & 07.07 & 1993 & 188 & $148-035$ & 2 & 2 & 3 & 2 & 2 & has much snow \\
5 & TM & 17.07 & 1994 & 198 & $149-035$ & - & - & 4 & - & - & path 149 \\
6 & TM & 01.09 & 1996 & 245 & $148-035$ & - & - & - & 3 & - & has fresh snow \\
7 & TM & 18.07 & 1997 & 199 & $148-035$ & 3 & 3 & 5 & 4 & 3 & \\
8 & TM & 07.09 & 1998 & 250 & $148-035$ & 4 & - & 6 & 5 & - & \\
9 & TM & 27.08 & 2000 & 240 & $148-035$ & 5 & 4 & - & - & - & \\
10 & ETM+ & 21.07 & 2001 & 202 & $148-035$ & 6 & - & 7 & 6 & 4 & \\
11 & ETM+ & 09.08 & 2002 & 221 & $148-035$ & 7 & - & 8 & - & - & \\
12 & ETM+ & 14.08 & 2004 & 227 & $148-035$ & 8 & 5 & 9 & 7 & 5 & GLS2005, striping removed \\
13 & ETM+ & 26.07 & 2006 & 207 & $149-035$ & - & - & 10 & - & - & path 149, striping removed \\
14 & TM & 11.08 & 2009 & 223 & $149-035$ & - & - & 11 & - & - & path 149 \\
15 & ETM+ & 12.08 & 2009 & 224 & $148-035$ & 9 & 6 & - & 8 & 6 & GLS2010, striping removed \\
16 & TM & 23.08 & 2010 & 235 & $148-035$ & - & - & 12 & 9 & 7 & \\
17 & TM & 10.08 & 2011 & 222 & $148-035$ & 10 & - & - & - & 8 & has clouds \\
18 & OLI & 14.07 & 2013 & 195 & $148-035$ & 11 & 7 & 13 & 10 & 9 & \\
19 & OLI & 24.07 & 2014 & 205 & $149-035$ & - & - & 14 & - & - & path 149 \\
20 & OLI & 04.07 & 2015 & 185 & $148-035$ & - & - & 15 & 11 & - & has much snow \\
21 & OLI & 21.08 & 2015 & 233 & $148-035$ & - & - & - & - & 10 & \\
\hline
\end{tabular}

the following, some prominent observations are described for each subregion.

\subsection{Observable glacier flow and terminus fluctuations}

\subsubsection{Subregion (1): Baltoro}

In subregion (1) Baltoro Glacier and its numerous tributaries dominate the scene (Fig. 2). With few exceptions, all glaciers show continuous and near-steady flow. Despite the easily recognizable high flow velocity of the main glacier, its terminus remains in about the same position. Supraglacial lakes across its surface appear and disappear but are easily traceable markers for the surface flow. Towards the upper parts of the glacier (to the right of the image), flow velocity seems to increase, because tracing features becomes increasingly difficult. In the accumulation region, flow dynamics are difficult to follow due to a lack of traceable features and the high variability of snow extent. However, in the lower right of the image, steep snow-covered glacier headwalls (facing north) and some deep crevasses reveal very high flow velocities. The flow speed here is high enough that the 1-3-year time step between images fails to provide the impression of continuous flow; instead it more looks like a nervous shaking.

As the animations are particularly useful for recognizing changes, the advancing fronts of several rather small glaciers with narrow and/or heavily debris-covered tongues are also easily visible. In most cases it would have been nearly impossible to spot these changes from comparison of image pairs alone. This is also the case for several advancing glaciers in the lower part of the image. Two surge-type glaciers (Trango and Muztagh in Fig. 2) with distorted moraines and a clearly visible variability in surface elevation can be seen to the north of Baltoro. To the south of them is the surge-type Liligo Glacier, which has been studied in detail before (e.g. Belò et al., 2008). This glacier reached its maximum extent around 1998 and was in its downwasting or quiescent phase afterwards. As the animations cover the surge and post-surge periods, the rapid advance of the front during the surge and the following thinning and disconnection of the lower tongue can be traced very well. Three of the four rather small glaciers in the southwest corner of the image (marked with an " $\mathrm{x}$ " in Fig. 2) show a behaviour that is similar to Liligo, in particular the one to the very left. At the same time, the terminus of the glacier to its right goes slightly back and forth several times. 


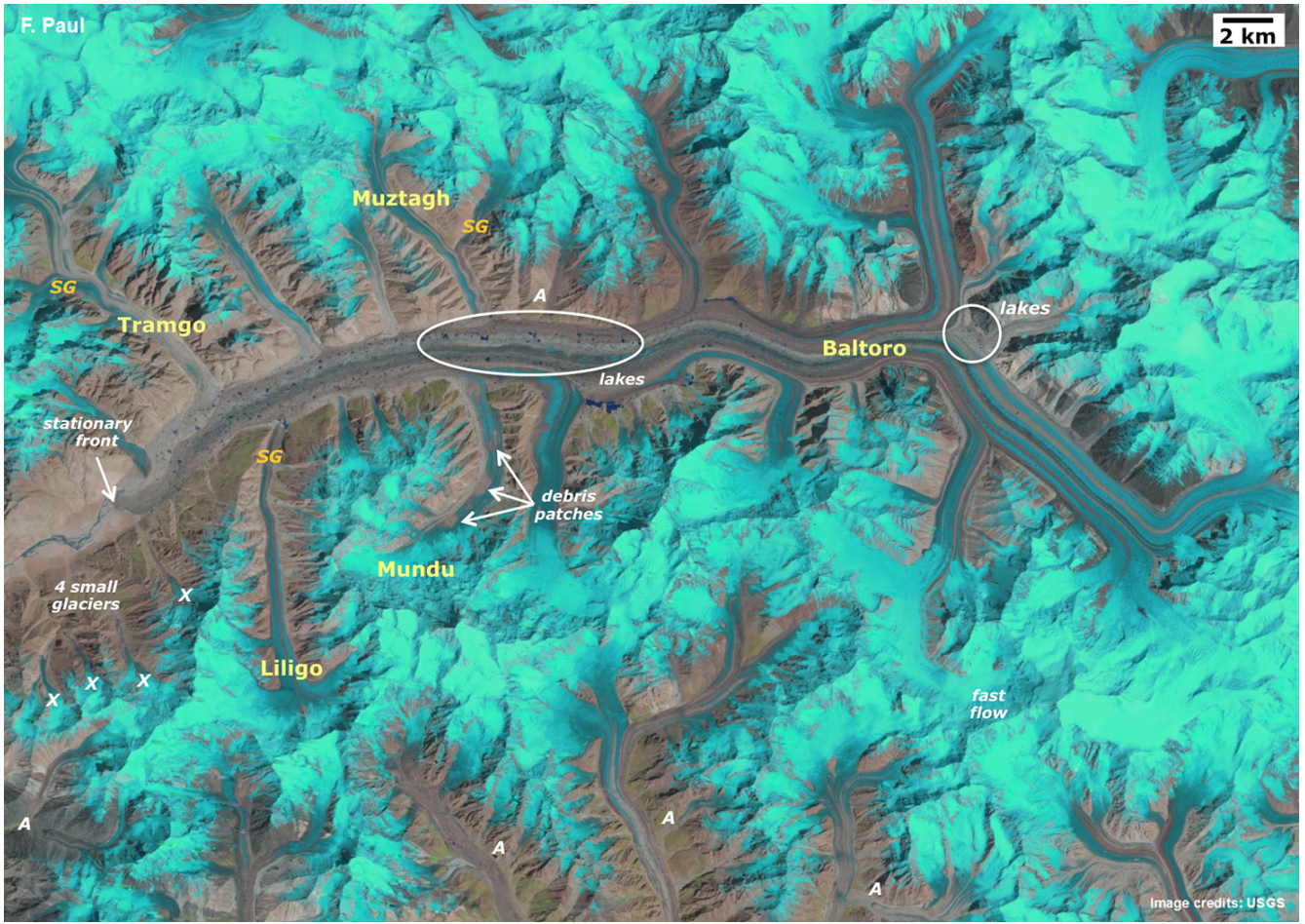

Figure 2. Subregion (1) (Baltoro) shows the tongue of Baltoro Glacier and its surrounding tributaries. SG (orange): actively surging glacier, SG (white): surge-type glacier (only on Figs. 4 and 5), A: advancing glacier. The Landsat scene 148-035 is from 14 August 2004

\subsubsection{Subregion (2): Panmah}

In the Panmah region (Fig. 3, subregion (2)), the variability in late summer snow extent, and the differences between the behaviour of the steady-flowing and actively surging glaciers are easily recognizable. While the large tongues of Biafo, Choktoi and Nobande Sobonde (NS) glaciers show the steady flow typical of non-surge-type glaciers, several (partly tributary) glaciers show strong advances (First Feriole, Shingchukpi), sudden onset of fast flow (Drenmang), or mass waves travelling down glacier (Chiring), and most of them finally collide with other glaciers (e.g. Maedan, Chiring) and create the well-known distorted and looped moraines (Hewitt, 2007). Also apparent is the asynchronous nature of the advance/retreat (or downwasting) phases. While Chiring Glacier finished its surge before 1998 (cf. Hewitt, 1998), other glaciers either started to surge around 2000 (First Feriole), were already in full surge mode then (e.g. Shingchukpi), or began to surge later (e.g. in 2006 for Drenmang). The surge of First Feriole glacier started while the ice masses from the previous surge were still down and backwasting in the valley floor. This gives the impression of one retreating and one advancing terminus at the same time. As in the Baltoro region, the termini of many of the much smaller surrounding glaciers are either stationary or advancing slowly. Some of the advancing glaciers have a terminus width of only 1 or 2 pixels but their changes can be easily followed in the animation.

\subsubsection{Subregion (3): Skamri}

The variability described above for subregion (2) is also apparent in subregion (3), as depicted in Fig. 4. Many of the surge-type glaciers are actively surging during the period of observation and only a few are in their quiescent phase. The smaller non-surge-type glaciers are either stagnant or slightly advancing, while the large debris-covered glaciers are stagnant and downwasting. A wide range of terminus advance rates is apparent as well. While one glacier (North Chongtar) advances very slowly (and might not be identified as being surge-type from its advance rate), others advance rapidly and strongly. They partly merge for some time with a larger main glacier (Sarpo Laggo and Skamri). As some of these glaciers (marked with an " $x$ " in Fig. 4) retreat back to their former positions over the remainder of the time period, the looping of the animations creates the impression that they are pulsating. This is different for South Chongtar Glacier, which has a downwasting and retreating ice mass from a previous surge in front of its more or less stagnant terminus. However, on closer inspection, one can see a surge front, a somewhat wider and advancing region up-glacier that is travelling down towards the stagnant terminus, likely indicating a forthcoming surge. If this is already termed a surge, then this glacier is in its quiescent and surge phase at the same time (demon- 


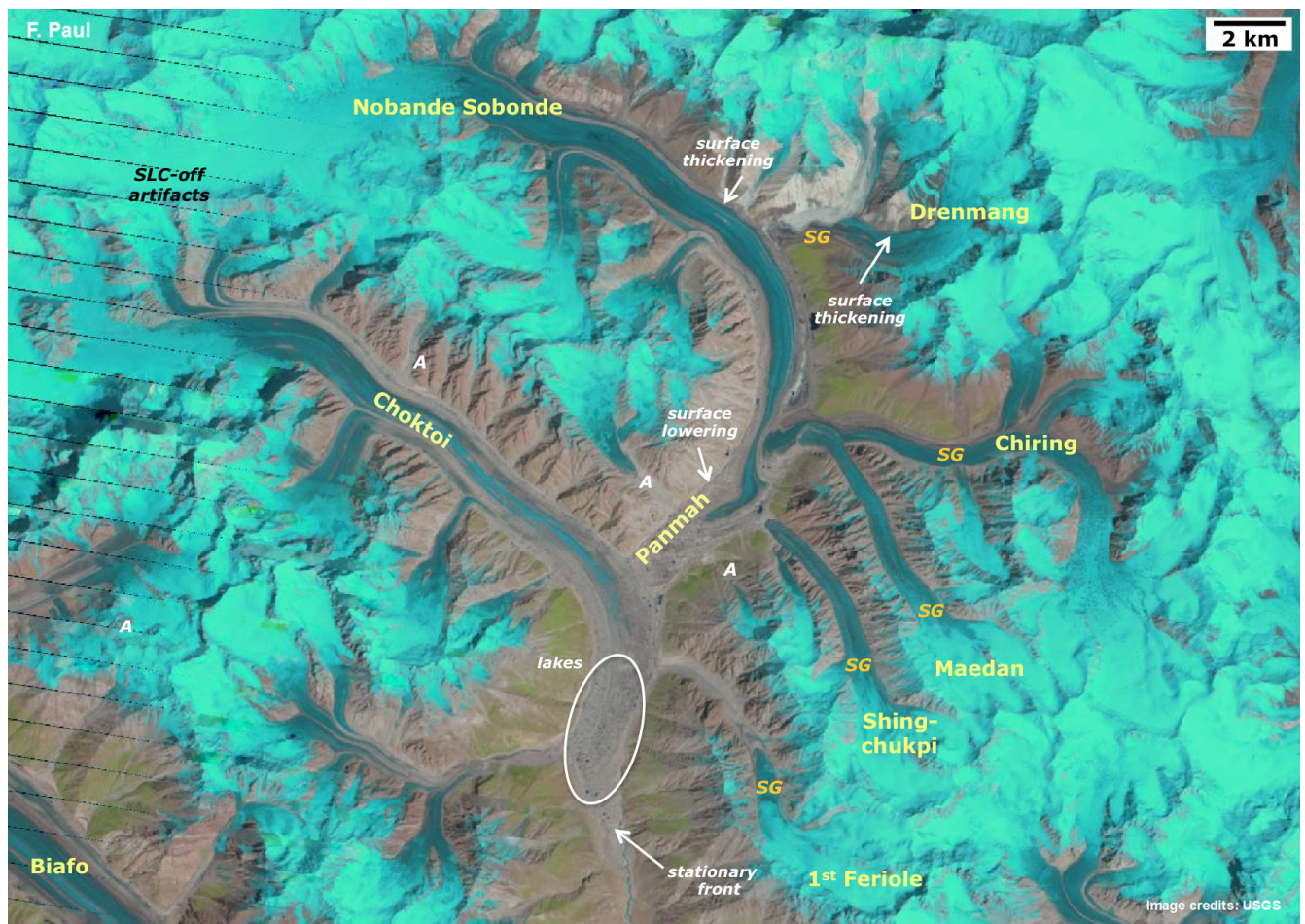

Figure 3. Subregion (2) (Panmah) shows the region around Panmah and Choktoi glaciers with surrounding tributaries; annotations and Landsat scene as in Fig. 2.

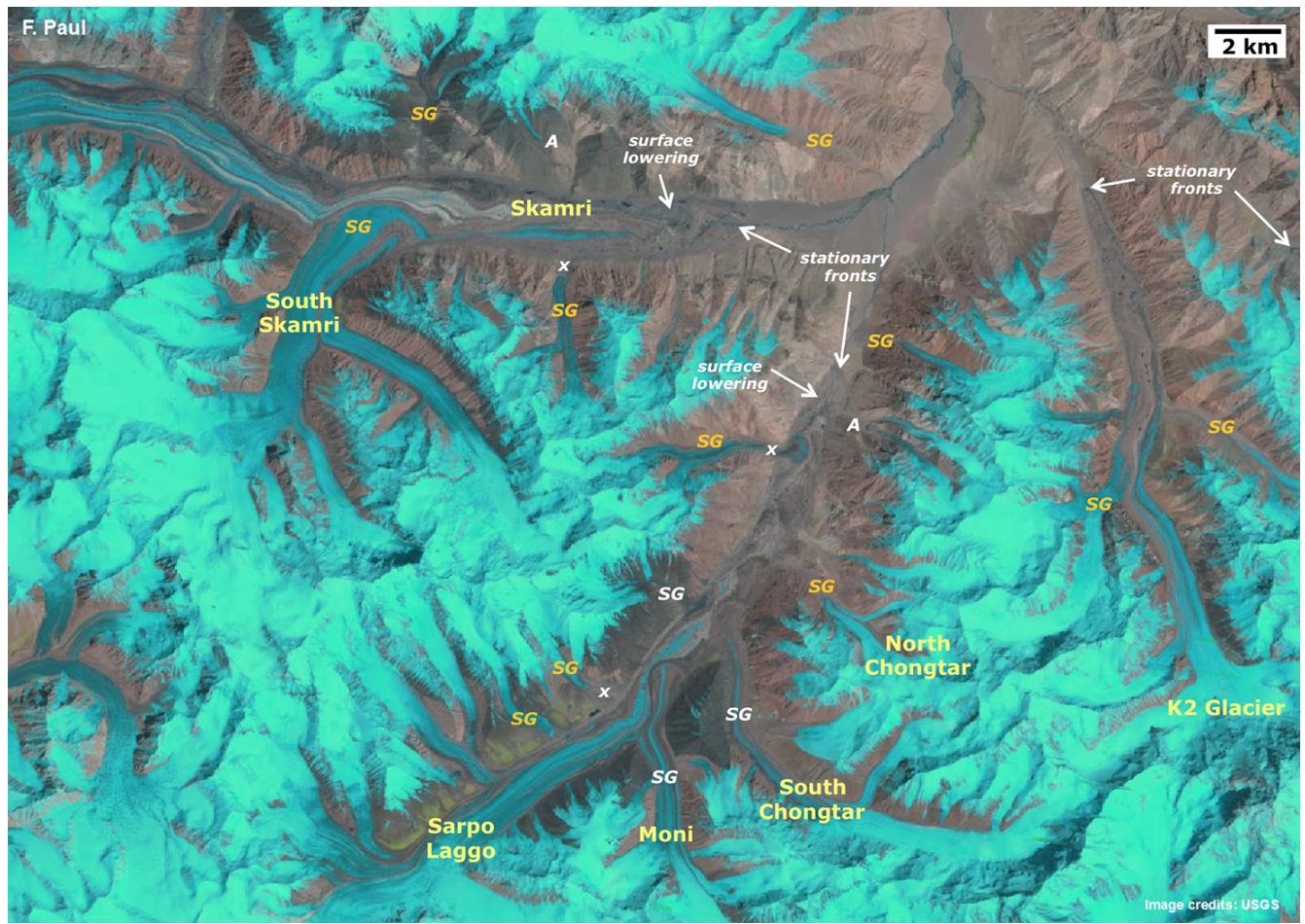

Figure 4. Subregion (3) (Skamri) shows the region between Skamri and Sarpo Laggo glaciers; annotations and Landsat scene as in Fig. 2. 
strating the difficulties for using the terminology correctly at a given time).

The small glacier on the opposite side of the valley is also advancing and might again (as in 1977) surge down to the tongue of Sarpo Laggo Glacier. Moni Glacier (Fig. 7) shows some interesting interaction with Sarpo Laggo. It seems that the lobate tongue of Moni (resulting from a previous surge) blocked the flow from Sarpo Laggo for some time and a fast flow event within the blocked ice mass advected the lobate structure from Moni Glacier quickly down valley for some years, as has also been observed for several surging glaciers in the Pamir (Kotlyakov et al., 2008). During and towards the end of this event, a substantial thinning of Sarpo Laggo can be observed upstream. From the moraine deformation visible in the last images, it also seems that Moni Glacier was again pushing into Sarpo Laggo, maybe starting its next surge. A similar interaction might also happen for South Skamri and Skamri glaciers. The animations reveal the increasing blocking of the flow of the main glacier by the surge of its tributary, South Skamri Glacier. So far, Skamri Glacier has not reacted to this blocking, but a sudden push of the distorted moraine in the upper left is already visible (see also Fig. 3c in Quincey et al., 2015). It remains to be seen if this push will catch up with the still ongoing surge of South Skamri.

\subsubsection{Subregion (4): Shaksgam}

In subregion (4) such a short-lived high-speed push event can be seen on Crown Glacier. The most massive surge can be seen for North Crown Glacier that has also reactivated the downwasting ice masses from a previous surge of a similarsized neighbouring glacier in its own surge (cf. Fig. 8 in Quincey et al., 2015). This glacier also shows a mass wave that is travelling down to the front creating the strong advance. Several other larger glaciers in the region are also advancing or even surging, depending on the definition of a surge. The ongoing surge of Tatulu Guo Glacier, shown in the upper right of Fig. 5, has also been described by Quincey et al. (2011). Several smaller glaciers show either stationary or slowly advancing fronts.

\subsection{Surface elevation changes}

As mentioned above, changes in surface elevation can be followed in the animations, in particular where there are stable lateral moraines. Changes observed include the thickening/thinning pattern typical of surging glaciers that occurs as a surge front propagates down glacier (as for Chiring, Drenmang and North Crown glaciers), as well as the downwasting of the stagnant tongues of several of the large debris-covered glaciers, in particular in subregion (3) (Sarpo Laggo, Skamri). There are also glaciers where no elevation changes can be detected, such as Baltoro and Choktoi glaciers, where flow appears to be stable. Rather interesting is also the surface lowering of Panmah Glacier (the lower part of Nobande Sobonde) in subregion (2), which occurs despite additional mass input from surging tributaries (Chiring and Shingchukpi). More subtle are the elevation increases and decreases that result from flow blocking such as that which characterizes the interaction between Moni and Sarpo Laggo or Drenmang and NS glaciers. In particular the latter can also be seen in the study by Gardelle et al. (2013), who determined elevation changes over the 2000-2008 period using differencing of two digital elevation models (DEMs). The animations reveal how these changes took place and how they were related to other changes associated with a glacier surge, such as frontal advance/retreat and velocity changes.

\subsection{Lakes and debris cover}

Another form of variability can be seen in the numerous (hundreds) supraglacial lakes and ponds covering the lower parts of Baltoro Glacier (subregion (1)), Panmah (subregion (2)) and some other glaciers. These lakes seem to be rather short-lived (about 2-3 years), limiting their use for determining flow velocities by feature tracking to a 1-year period. Most of the lakes are about the same size but their shape varies rather strongly from scene to scene. For Baltoro Glacier, it is apparent that supraglacial lakes often form in zones of compressive flow (where larger tributaries join), indicating that surface meltwater is not efficiently drained. However, it also has to be considered that the images are taken at different dates each year and that the extent and level of the lakes varies over a year in response to changing melt conditions and rainfall. Stationary lakes outside the lateral moraines also change size over time.

Supraglacial debris occurs in form of the typical flowparallel moraines (where they first appear) that often spread out to create a complete debris cover near the terminus, in the form of distorted (wave-like) bands where glaciers with unsteady flow interact, or in the form of local debris accumulations from rock fall events. One glacier (Mundu) in subregion (1) has regular and similar-sized patches of debris on its surface, indicating periodic rock fall activity.

\subsection{Apparent movement of stable terrain}

Finally, subregion (2) shows local movement of terrain that is actually stable, mostly along mountain peaks and ridges. This is likely the result of the use of different DEMs to orthorectify the satellite images. As this apparent movement is concentrated on regions outside the glaciers (i.e. on "stable" terrain), an algorithm for calculating flow velocity would obtain a considerable surface displacement in these regions, which has to be removed manually before assessment of the accuracy of glacier velocities over stable terrain can be performed. The animated images clearly reveal such regions, helping to determine the quality of the orthorectification for an entire time series and identify the obviously unstable re- 


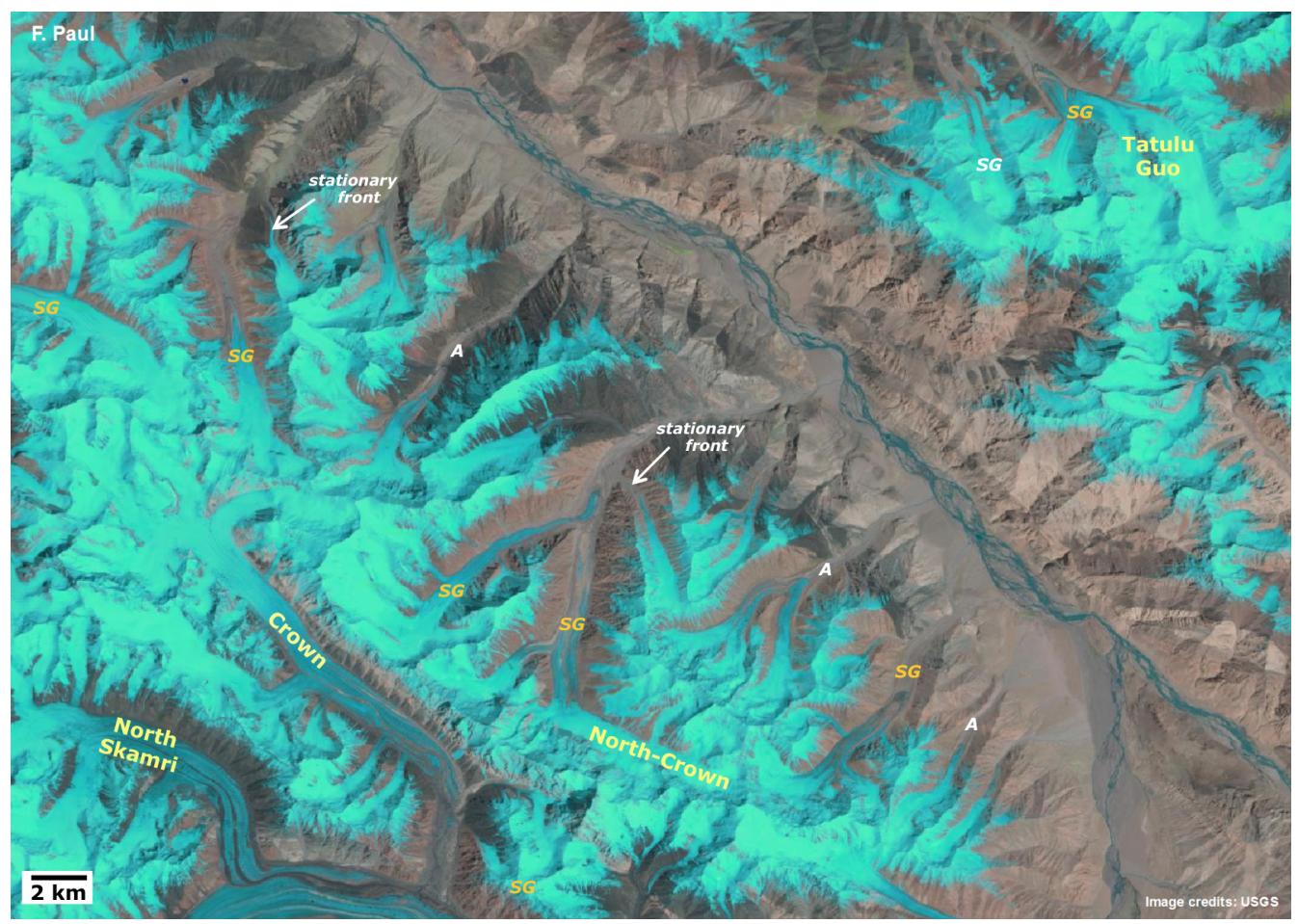

Figure 5. Subregion (4) (Shaksgam) shows the region to the north of Skamri Glacier to both sides of the Shaksgam Valley; annotations and Landsat scene as in Fig. 2.

gions for the post-processing of velocity data (e.g. Kääb, 2005).

\section{Discussion}

\subsection{Creating animations from image time series}

The animations presented here would not have been possible without the accurate and consistent orthorectification of all satellite scenes by USGS. Indeed, errors in the DEM used for orthorectification translate into incorrect pixel positions that change when a different DEM is used for orthorectification, especially in high relief and steep terrain (see Sect. 3.4). However, for relatively flat glacier tongues, this effect is small and does not obscure the much larger changes due to glacier flow. It must also be mentioned that the animations are created from image quick-looks that are freely provided (earthexplorer.usgs.gov) (a) in full resolution, (b) geocoded, (c) with a small file size (about $10 \mathrm{MB}$ ), (d) in false colour (revealing glaciers) and (e) with colours and brightness values well balanced among all scenes. The latter property is an invaluable asset for viewing the animations. If brightness values or colours were more variable, it would be impossible to look at the animations due to a stroboscope effect. Hence, the consistency of the processing line is responsible for the clarity with which the glacier dynamics can be seen.
With the processing line being established, scenes must have been acquired over a sufficiently long time period (at best each year) and be available in the USGS archive. The former point is not necessarily the case for the first years of Landsat operation and during its commercial phase (see Goward et al., 2006). The latter point (transfer of scenes from non-USGS archives to USGS) is an ongoing process that will continuously expand the possibilities for other regions. Data availability is also restricted after 2003, when the scanline corrector of ETM+ failed and intense striping degraded the usefulness of the scenes. It comes with some luck that three of the post-2003 scenes from ETM+ used here were in the Global Land Survey (GLS) 2005 and 2010 catalogues and had the striping more or less removed (i.e. filled with information from other scenes). Surprisingly, this filling of missing lines had no noticeable effect on the boundaries or surface features of the quickly changing glaciers, e.g. due to clouds or different snow conditions. Apart from some remaining artefacts, the former regions with missing lines can only be identified by carefully analysing the individual images. This implies that great care has been taken to correct the striping and/or that the replacement scenes were acquired close to the date of the corrected scenes.

On the more practical side, it is important that appropriate scenes are available. Key requirements are that all scenes are taken in each year near the end of the ablation period (with as much glacier ice exposed as possible) at about the same day 
(to avoid strong changes due to shadow) and without clouds. While it was not possible to have identical extents of snow cover on all images used in this study (resulting in a rather nervous flickering when animated), the variability of shadow extent is rather limited due to the high solar elevation. Clouds were an issue in some years and regions (e.g. in 2008), but the large data gap between 2004 and 2009 is mostly due to missing stripe-filled quick-looks as suitable ETM+ scenes are available for 2005, 2006 and 2007. For the Panmah region in the east, it was possible to include additional scenes from the neighbouring path (149-035) in 1990, 1994 and 2006 (see Table 1), resulting in smoother transitions. Splitting the region into subregions thus also provided a higher flexibility for selection of good images.

The final step in creating the images was the selection of the most useful scenes for each subregion. This was a compromise between (a) using as many largely cloud-free images as possible, (b) having a more or less constant time step of 1-3 years between each image, (c) avoiding strong changes in reflectivity due to seasonal snow, and (d) capturing the relevant processes that sometimes occur only in a specific year. As Table 1 reveals, it was not really possible to satisfy point (b) for any of the regions without compromising the other points. This results in a non-equidistant temporal difference between the images (from 1 to 5 years) with potential effects on the perception of flow velocities (e.g. flow seems faster with 3-year than with 1-year time steps). Obvious changes in flow velocity have thus to be interpreted with great care. As a compromise, for some regions, more individual images are provided on the separate server (http://cryoportal.enveo.at/glaciers.html) than were actually used for the animations. Experimenting with these additional images is encouraged (see Sect. 4.3).

Overall, the animations presented here provide an overview on glacier and landscape dynamics over a period of 25 years that cannot be created in all regions of the world. Apart from the above criteria related to the availability and selection of images, glaciers also have to be large and structured enough to reveal flow dynamics. Otherwise, it will be mostly the changes in extent that can be followed, but this might be of interest as well.

\subsection{Advantages of the animations compared to other methods}

As described in the introduction, several possibilities exist to visualize glacier changes (e.g. front variations) or dynamics (e.g. flow fields and their changes over a given time period) in a quantitative way (e.g. overlay of colour-coded and/or annotated outlines or maps, side by side comparisons). The animations on the other hand, provide information and insights that are complementary to the above classic (quantitative) ways. Apart from the fact that the animations reveal the temporal evolution of otherwise very slow processes in a much faster (time-lapse) mode and provide a true dynamic feel- ing, they also give a holistic view of changes taking place at the same time (e.g. terminus fluctuations, elevation changes, flow velocities) that is nearly impossible to obtain from static maps. Examples are the stagnant downwasting lower tongues of Skamri and Sarpo Laggo glaciers, and the mass wave that is travelling down Chiring Glacier at high velocity, resulting in a fast and strong advance of the terminus. This easily visible combination of effects might ultimately help to establish a more comprehensive definition of surge-type or surging glaciers that seemingly needs to be expanded to correctly capture the full variability of possible glacier dynamics.

When looking at the benefits of animations more systematically, they can be roughly grouped into three categories: (I) more subtle insights facilitating process understanding, (II) new scientific information, and (III) technical advantages. Insights of category (I) are

a. how a glacier flows in general and how a main stream of ice is fed by its tributaries;

b. the succession or timing of events for individual glaciers and the entire region;

c. understanding of glacier dynamics for the wider public that is not used to interpret colour-coded velocity fields or line graphs.

Insights of category (II) include

a. identification of surging glaciers using a range of criteria that are all visible at the same time (e.g. advance rates of the terminus, internal velocity changes, travelling of mass waves through the glacier, typical downwasting pattern after a surge);

b. for long time series, information retrieval is maximized when full surge cycles are captured;

c. a holistic and at the same time very detailed view of decadal glacier variability and dynamics in a large region;

d. the gradual downwasting of mostly large, stationary and debris-covered glaciers can be followed through time;

e. the very high flow velocities of the ice in steep parts of accumulation regions that are not captured by traditional methods such as offset tracking from optical (contrast issue, stationary crevasses) or microwave data (radar shadow, decorrelation);

f. the rapid changes (formation and decay) of supraglacial lakes;

g. the identification of very tiny (1-2 pixel) debris-covered glacier fronts (that are hard to recognize in individual images) and their changes through time; 
h. movement of terrain that should be stable but is not, due to different DEMs being used for orthorectification (important for accuracy assessment of velocity products).

In principle, most of the above points can also be detected if individual images are uploaded in an image browser by scrolling through them back and forth. So what are the technical advantages (category III) of using the automated animations?

a. On the practical side, the manual scrolling through the time series can only be performed a few dozen times before either the finger becomes tired or the scroll wheel stops working;

b. similarly, an automated animation allows the mouse to be used to point out specific details;

c. more technically, for large data sets (e.g. more than six images) it might not be possible to include all images in the series within a single scroll;

d. scientifically, the constant repetition rate of the individual images cannot be achieved by manual scrolling (important to recognize changes in flow velocity);

e. visually, the back and forth movement of the ice is disruptive and does not provide the same category (I) insights (e.g. of continuous flow);

f. finally, the repetition rates can be adjusted (lowered) to study specific changes in detail.

Of course, animated flicker images provide similar advantages, but they are normally restricted to two images and do thus not show the full temporal development over a longer time. They also suffer from the back and forth effect (IIIe) that hinders the impression of continuous flow. However, they can be very practical for rapid change detection when image conditions are about the same.

\subsection{Educational use of the animations}

As mentioned above, there is certainly potential for creating or using animations for educational purposes. While the visualization of glacier flow dynamics itself might be of interest for teaching, public communication or exhibitions, classroom experiments might look at using other images for each time series (fewer/more), changing the repetition rate, analyse effects of the looping, and adding annotations such as a time bar. Remote-sensing-related questions might focus on the spectral properties of ice and snow and the false colour composites used, spatial resolution and visibility of details, or the value of long-term time series and free data availability. The latter might be further explored in hands-on lectures or summer schools (e.g. Manakos et al., 2007) by creating such animations for other regions with sufficient temporal coverage. The animations might also help understanding of natural variability over timescales that are not available from any other source. Finally, the time-lapse mode compresses a 25-year development into $1 \mathrm{~s}$, i.e. compared to reality, glacier flow is shown about 800 million times faster. This fact might be explored on a more philosophical level.

\subsection{Flow velocities in accumulation regions}

Due to the lack of contrast and traceable features, optical sensors usually fail to provide information on flow velocities in the accumulation regions of glaciers (e.g. Quincey et al., 2009; Dehecq et al., 2015). The same is true for microwave sensors in steep terrain due to radar shadow and layover effects (e.g. Rott, 2009). However, high-resolution missions such as TerraSAR-X have improved the situation to some extent (Rankl et al., 2014) and show localized regions of fast flow, even at the highest elevations of glaciers. The animations reveal that the regions of fast flow are rather widespread in steep accumulation regions and not adequately captured by current velocity maps.

\subsection{Identification of surge-type glaciers}

As mentioned in the study by Sevestre and Benn (2015) and several previous investigations (e.g. Copland et al., 2011; Hewitt, 2007; Quincey et al., 2011; Rankl et al., 2014), the central Karakoram has a high abundance of surge-type glaciers of which many have actively surged in the past 25 years. As "normal" glacier advances are basically a consequence of changed climatic conditions, while surges largely result from internal mechanisms (e.g. Jiskoot, 2011; Meier and Post, 1969; Raymond, 1987; Sharp, 1988), it is important to distinguish the two glacier types. However, the animations reveal a large heterogeneity of the surging glaciers in terms of size, hypsometry, exposure, advance rates, surge durations, etc. that clearly overlap with the characteristics of non-surgetype glaciers.

While the frontal advance rate, duration or distance are only three of many criteria used to identify glaciers as surging (see overview in Sevestre and Benn, 2015), the above examples reveal that there is actually a continuum of advance rates that allows no clear separation between surging and advancing glaciers. The same is true for advance durations that vary from short pulses (1-2 years) of rapid advance (Drenmang) to slow advances taking more than 10 or even 25 years (First Feriole, North Chongtar). Similar advance rates and durations can also be found for non-surgetype glaciers. Moreover, glaciers of nearly any size seem to surge, from small $\left(<1 \mathrm{~km}^{2}\right)$ and steep, to large $\left(>10 \mathrm{~km}^{2}\right)$ and flat. Hence not all the advancing glaciers in the animations need be surging glaciers. The related annotations in Figs. 2-5 (A for advancing, SG for surge-type glacier) are thus subjective to some degree and can change when other criteria are applied. 
As previous studies have shown (e.g. Raymond, 1987), some glacier surges involve considerable changes in flow velocity, surface elevation and extent. Such quasi-parallel changes are recognizable in the animations for some glaciers in subregion (2) (Chiring, Drenmang). However, in several cases, only some of these changes occur and for this study the characterization is based on easily recognizable advances, consistent with previous literature (Copland et al., 2011; Rankl et al., 2014; Quincey et al., 2014) and historic satellite images (MSS scene from 1977). However, glacier 14 in Fig. 6 of the study by Rankl et al. (2014) is only marked as advancing in this study, rather than surging, and this is certainly subjective. On the other hand, glacier 15 in their study (North Chongtar) is identified as surge-type but has actually been advancing slowly since the 1970 s, i.e. for more than 40 years. This gives rise to the question of how slow and prolonged an advance can be for it still to be characterized as a surge.

Previous studies that have characterized surge-type glaciers according to their topographic characteristics (e.g. area, length, slope, debris cover) have found a tendency for surge-type glaciers to be longer, less steep, with more branches, and being more fully debris-covered than nonsurge-type glaciers of similar size (e.g. Clarke et al., 1986; Barrand and Murray, 2006; Rankl et al., 2014; Sevestre and Benn, 2015). In contrast, many of the surge-type or surging glaciers in the study region are comparatively small (2-20 $\mathrm{km}^{2}$ range) and steep, debris-free (apart from medial moraines), and they have single- or dual-basin accumulation regions. It is assumed that this difference is also a result of a failure to clearly distinguish between surging tributaries and non-surging trunk glaciers in previous studies. Moreover, these steep, small and largely debris-free glaciers could have been missed in previous assessments, as it is very difficult to identify them as surge-type when they are in their quiescent phase.

Another possibility for separating surging from normal advancing/retreating glaciers is related to their specific postsurge behaviour (i.e. the quiescent phase). As the animations reveal (for glaciers that do not flow into another glacier from the outset), the way the extended tongue down-wastes and disintegrates after a surge is rather specific. It seems (e.g. for Liligo in Fig. 2 or Shingchukpi in Fig. 3) that the entire surged ice mass is transformed into dead ice after a surge and decays by downwasting, similar to the ice resulting from a dry calving event. After some years, this downwasting separates the lower part of the surged ice mass from an upper part at about $1 / 4$ to $1 / 3$ of its length (when measured from the terminus). This points to thicker ice near the terminus relative to the rest of the tongue, as ablation would normally be higher at the lower elevations of the terminus (assuming clean ice). This specific pattern of dead-ice downwasting after a surge is rather unique for surge-type glaciers and might be a good criterion for identifying them.

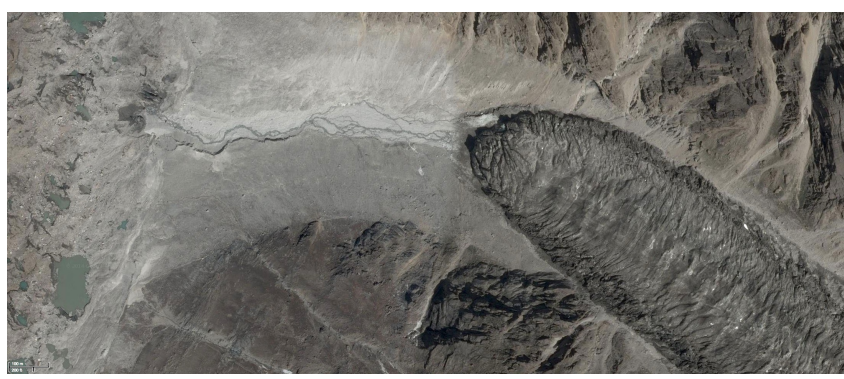

Figure 6. The still-advancing (surging) tongue of First Feriole Glacier in the Panmah subregion. The image is a screenshot from Google Maps and was acquired on 6 June 2014.

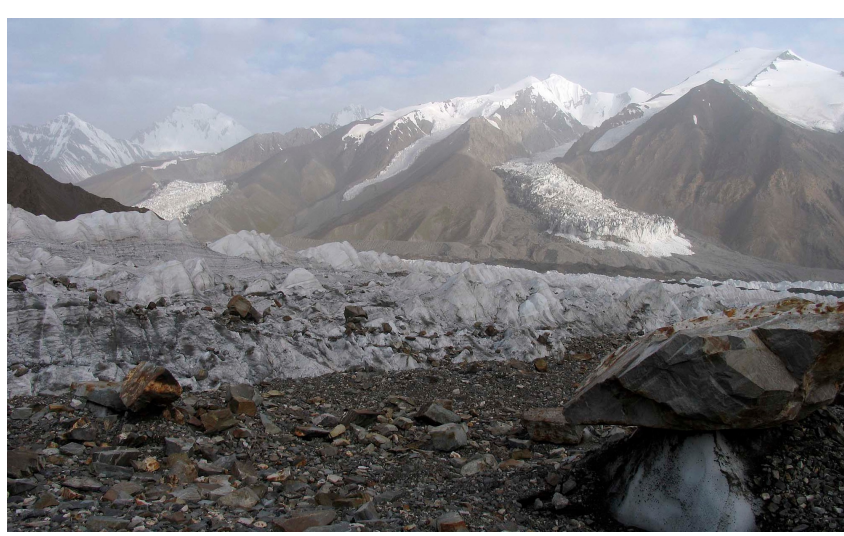

Figure 7. A surging tributary of Sarpo Laggo Glacier can be seen to the right of the centre of the image, as viewed from Moni Glacier in the foreground (see Sect. 3.1.3 for details). To the left of the centre of the image, another unnamed surging glacier is visible. The photo was taken in 2006 by Michael Beck (www.himalaya-info.org).

\subsection{Repeat surges}

Many of the glaciers in the study region have reportedly surged during the past century (cf. Copland et al., 2011), and historic satellite imagery (e.g. the MSS scene from 1977) reveals different extents of the surge-type glaciers analysed here. For example, First Feriole Glacier was in contact with Panmah Glacier in 1977 and the latest high-resolution satellite image (from 6 June 2014) available in Google Earth (Fig. 6) reveals that the glacier is still in full surge mode and might re-establish contact with Panmah Glacier in 2 or 3 years, resulting in a ca. 40 -year surge cycle. A tributary of Sarpo Laggo in subregion (3) (no. 45 in Copland et al., 2011; no. 16 in Rankl et al., 2014) was in contact with the main glacier back in 1977, 1991 and again in 2007, indicating a ca. 15-year cycle. An image of its surge front from July 2006 is shown in Fig. 7. This is about 1.5 years before the glacier came into contact with Sarpo Laggo Glacier. Such a periodic repetition of surges is also a good indicator of surge-type behaviour. 


\subsection{Mass budgets}

As glacier surges might have non-climatic controls, the frontal changes of the non-surge-type glaciers can be better interpreted in climatic terms. In all four subregions, these glaciers have had either stable or advancing termini over the 25-year period (see Sect. 3.1). This implies that past mass budgets have generally been close to zero or even positive (e.g. Janes and Bush, 2012). Unfortunately, there is only indirect evidence for this as these glaciers are in general too small to obtain reliable geodetic mass budgets from DEM differencing (Gardelle et al., 2013). On the other hand, the characteristic mass loss at higher elevations and gain in the ablation region is easily visible for glaciers that surged after 2000 in the elevation difference grids presented by Gardelle et al. (2013). The resulting near-zero mass budgets of these glaciers are, however, only half the story. On a longer timescale, the surged ice masses also melt down and result in an overall mass loss of the glacier. For several glaciers the downwasting and mass loss after a surge can be traced in the animations. Downwasting also occurs in the ablation regions of some larger, debris-covered glaciers that are influenced by surges of tributaries (Panmah, Sarpo Laggo or Skamri). In this case it might be possible that the tributary surges move the ice of the main glacier to lower elevations where the debris cover is insufficient to protect the ice from melting. When considering these complex dynamic interactions, it seems appropriate to exclude surge-type glaciers from climate change impact studies that are related to timescales shorter than a full surge cycle.

\section{Conclusions}

This study discussed and presented (in the Supplement) animated satellite image sequences from four regions in the central Karakoram mountain range, covering a 25 -year time period. The high repetition rate of $1 / 10 \mathrm{~s}$ per frame gives the impression of continuous glacier flow and reveals changes in morphology and dynamics with a clarity that cannot be achieved with side by side comparison of static images or colour-coded glacier outlines from different points in time. Though changes are not determined in a quantitative way, the time-lapse mode of the animations provides insights that are difficult to obtain otherwise. Apart from really seeing how glaciers flow and interact, the particular advantage is the holistic view of glacier changes, showing advance/retreat, elevation changes and surface flow of multiple glaciers in a region all at the same time. This is particularly useful for identification of surging glaciers, which show all or several of these changes in parallel.

The animations also reveal variations that have not been reported before (e.g. the high flow velocities in steep accumulation regions) and that would be difficult to detect using other methods (e.g. advances of very small debris- covered glaciers). The automated looping through all images has a number of technical advantages over the routinely used flicker images (e.g. full time series) and manual browsing (e.g. constant repetition rate) that allow a more in-depth analysis of specific changes. There is great potential for using the animations for educational purposes and further experimenting with the combination of individual images (provided separately) and the frame interval. Generating such animations for other glacierized regions would likely provide additional insights, but it has to be considered that data availability (e.g. due to clouds, snow cover, or unfilled ETM+ stripes) might limit the possibility of creating such dense time series.

As previous studies have shown, the study region is characterized by abundant surge-type glaciers, of which several were actively surging during the observation period 1990-2015. However, the animations reveal a wide spectrum of surge types from short-lived velocity pulses (without frontal advance), to mass waves travelling down-glacier (with strong frontal advance), to highly variable advance rates, distances and surge durations, all indicating that no single definition can be used to identify them as surge-type. It seems that several relatively small, steep and debris-free glaciers surge as well. As they lack the typical morphological evidence for surging, such as looped or distorted medial moraines, their surges can only be recognized from timeseries analysis. Overall, the surges are generally out of phase with one another and some glaciers seem to surge periodically with repeat cycles of a few decades. The considerable overlap between the characteristics of surge-type and nonsurge-type, but advancing, glaciers causes problems for classification.

The animations reveal that large glaciers with steady flow (Baltoro, Choktoi) have stationary terminus positions and stable surface elevations, while those influenced by surging tributaries (Panmah, Sarpo Laggo, Skamri) have stationary fronts but show considerable downwasting. In the latter case the ice of the main glacier might have been pushed downstream by a tributary surge. Considering such complex interactions and the possible non-climatic control of glacier surges, it seems advisable to exclude surge-type glaciers from the sample when climate change impacts are investigated on a timescale shorter than the surge cycle.

\section{The Supplement related to this article is available online at doi:10.5194/tc-9-2201-2015-supplement.}

Acknowledgements. This study has been performed in the framework of the ESA project Glaciers_cci (4000109873/14/I-NB). All Landsat data were obtained from USGS. I would like to thank the scientific editor M. Sharp for his valuable comments and the careful review of the paper. Thanks are extended to B. Marzeion, D. Quincey and one anonymous referee for providing constructive reviews. S. Allen and P. Rastner gave helpful feedback to an earlier version of the paper. 
Edited by: M. Sharp

\section{References}

Barrand, N. E. and Murray, T.: Multivariate controls on the incidence of glacier surging in the Karakoram Himalaya, Arct. Antarct. Alp. Res., 38, 489-498, 2006.

Baumann, S., Winkler, S., and Andreassen, L. M.: Mapping glaciers in Jotunheimen, South-Norway, during the "Little Ice Age" maximum, The Cryosphere, 3, 231-243, doi:10.5194/tc-3-231-2009, 2009.

Belò, M., Mayer, C., Smiraglia, C., and Tamburini, A.: The recent evolution of Liligo glacier, Karakoram, Pakistan, and its present quiescent phase, Ann. Glaciol., 48, 171-176, 2008.

Bhambri, R., Bolch, T., Kawishwar, P., Dobhal, D. P., Srivastava, D., and Pratap, B.: Heterogeneity in glacier response in the upper Shyok valley, northeast Karakoram, The Cryosphere, 7, 13851398, doi:10.5194/tc-7-1385-2013, 2013.

Bolch, T., Kulkarni, A., Kääb, A., Huggel, C., Paul, F., Cogley, J. G., Frey, H., Kargel, J. S., Fujita, K., and Scheel, M.: The state and fate of Himalayan glaciers, Science, 336, 310-314, 2012.

Clarke, G. K. C., Schmok, J. P., Ommanney, C. S. L., and Collins, S. G.: Characteristics of surge-type glaciers, J. Geophys. Res., 91, 7165-7180, 1986.

Copland, L., Sylvestre, T., Bishop, M. P., Shroder, J. F., Seong, Y. B., Owen, L. A., Bush, A., and Kamp, U.: Expanded and recently increased glacier surging in the Karakoram, Arct. Antarct. Alp. Res., 43, 503-516, 2011.

Dehecq, A., Gourmelen, N., and Trouve, E.: Deriving large-scale glacier velocities from a complete satellite archive: Application to the Pamir-Karakoram-Himalaya, Remote Sens. Environ., 162, 55-66, 2015.

Diolaiuti, G., Pecci, M., and Smiraglia, C.: Liligo Glacier, Karakoram, Pakistan: a reconstruction of the recent history of a surgetype glacier, Ann. Glaciol., 36, 168-172, 2003.

Gardelle, J., Berthier, E., Arnaud, Y., and Kääb, A.: Region-wide glacier mass balances over the Pamir-Karakoram-Himalaya during 1999-2011, The Cryosphere, 7, 1263-1286, doi:10.5194/tc7-1263-2013, 2013.

Goward, S., Arvidson, T., Williams, D., Faundeen, J., Irons, J., and Franks, S.: Historical Record of Landsat Global Coverage: Mission Operations, NSLRSDA, and International Cooperator Stations. Photogramm. Eng. Rem. S., 72, 1155-1169, 2006.

Grant, K. L., Stokes, C .R., and Evans, I. S.: Identification and characteristics of surge-type 693 glaciers on Novaya Zemlya, Russian Arctic, J. Glaciol., 55, 960-972, 2009.

Hewitt, K.: Glaciers receive a surge of attention in the Karakoram Himalaya, EOS T. Am. Geophys. Un., 79, 104-105, 1998.

Hewitt, K.: The Karakoram Anomaly? Glacier expansion and the "Elevation Effect", Karakoram Himalaya, Mt. Res. Dev., 25, 332-340, 2005.

Hewitt, K.: Tributary glacier surges: an exceptional concentration at Panmah Glacier, Karakoram Himalaya, J. Glaciol., 53, 181-188, 2007.

Hewitt, K.: Glaciers of the Karakoram Himalaya, in: Glacial Environments, Processes, Hazards and Resources, Springer, Dordrecht, XX, 363 pp., doi:10.1007/978-94-007-6311-1, 2014.
Isaac, M.: GIFs go beyond emoji to express thoughts without words, The New York Times, Technology, available at: http://nyti.ms/ 1HIXkOZ (last accessed 1 November 2015), 3 August 2015.

Iturrizaga, L.: Trends in 20th century and recent glacier fluctuations in the Karakoram Mountains, Z. Geomorphol., 55, 205$231,2011$.

Janes, T. J. and Bush, A. B. G.: The role of atmospheric dynamics and climate change on the possible fate of glaciers in the Karakoram, J. Climate, 25, 8308-8327, 2012.

Jiskoot, H.: Glacier surging, in: Encyclopedia of Snow, Ice and Glaciers, edited by: Singh, V. P., Singh, P., and Haritashya, U. K., Springer, Heidelberg, 415-428, 2011.

Jiskoot, H. and Juhlin, D. T.: Surge of a small East Greenland glacier, 2001-2007, suggests Svalbard-type surge mechanism, J. Glaciol., 55, 567-570, 2009.

Kääb, A.: Combination of SRTM3 and repeat ASTER data for deriving alpine glacier flow velocities in the Bhutan Himalaya, Remote Sens. Environ., 94, 463-474, 2005.

Kääb, A. and Vollmer, M.: Surface geometry, thickness changes and flow fields on creeping mountain permafrost: automatic extraction by digital image analysis, Permafrost Periglac., 11, 315-326, 2000.

Kääb, A., Isakowski, Y., Paul, F., Neumann, A., and Winter, R.: Glaziale und periglaziale Prozesse: Von der statischen zur dynamischen Visualisierung, Kartographische Nachrichten, 53 , 206-212, 2003.

Kotlyakov, V. M., Osipova, G. B., and Tsvetkov, D. G.: Monitoring surging glaciers of the Pamirs, central Asia, from space, Ann. Glaciol., 48, 125-134, 2008.

MacGillivray, C.: How Psychophysical perception of motion and image relates to animation practice, in: IEEE 4th International Conference on Computer Graphics, Imaging and Visualization (CGIV 2007), 14-16 August 2007, Bangkok, Thailand, 81-88, 2007.

Manakos I., Kalaitzidis, C., and Perakis, K.: The Introduction of Remote Sensing into the Euro-pean knowledge society: an approach, in: 27th EARSeL Symposium "Geoinformation in Europe": European Association of Remote Sensing Laboratories, Bolzano, 581-588, 2007.

McNabb, R. and Hock, R.: Alaska tidewater glacier terminus positions, 1948-2012, J. Geophys. Res.-Earth, 119, 153-167, doi:10.1002/2013JF002915, 2014.

Meier, M. F. and Post, A.: What are glacier surges?, Can. J. Earth Sci., 6, 807-817, 1969.

Mukhopadhyay, B. and Khan, A.: Rising river flows and glacial mass balance in central Karakoram, J. Hydrol., 513, 192-203, 2014.

Paul, F., Kääb, A., Maisch, M., Kellenberger, T. W., and Haeberli, W.: Rapid disintegration of Alpine glaciers observed with satellite data, Geophys. Res. Lett., 31, L21402, doi:10.1029/2004GL020816, 2004.

Paul, F., Bolch, T., Kääb, A., Nagler, T., Nuth, C., Scharrer, K., Shepherd, A., Strozzi, T., Ticconi, F., Bhambri, R., Berthier, E., Bevan, S., Gourmelen, N., Heid, T., Jeong, S., Kunz, M., Lauknes, T. R., Luckman, A., Merryman Boncori, J. P., Moholdt, G., Muir, A., Neelmeijer, J., Rankl, M., VanLooy, J., and Van Niel, T.: The glaciers climate change initiative: Methods for creating glacier area, elevation change and velocity products, Remote 
Sens. Environ., 162, 408-426, doi:10.1016/j.rse.2013.07.043, 2015.

Quincey, D. J., Copland, L., Mayer, C., Bishop, M., Luckman, A., and Belo, M.: Ice velocity and climate variations for Baltoro Glacier, Pakistan, J. Glaciol., 55, 1061-1071, 2009.

Quincey, D. J., Braun, M., Glasser, N. F., Bishop, M. P., Hewitt, K., and Luckman, A.: Karakoram glacier surge dynamics, Geophys. Res. Lett., 38, L18504, doi:10.1029/2011GL049004, 2011.

Quincey, D. J., Glasser, N. F., Cook, S. J., and Luckman, A.: Heterogeneity in Karakoram glacier surges, J. Geophys. Res.-Earth, 120, 1288-1300. doi:10.1002/2015JF003515, 2015.

Rankl, M., Kienholz, C., and Braun, M.: Glacier changes in the Karakoram region mapped by multimission satellite imagery, The Cryosphere, 8, 977-989, doi:10.5194/tc-8-977-2014, 2014.

Raymond, C. F.: How do glaciers surge? A review, J. Geophys. Res., 92, 9121-9134, 1987.

Rott, H.: Advances in interferometric synthetic aperture radar (InSAR) in earth system science, Prog. Phys. Geog., 33, 769-791, 2009.
Scambos, T. A., Dutkiewicz, M. J., Wilson, J. C., and Bindschadler, R. A.: Application of image cross-correlation to the measurement of glacier velocity using satellite image data, Remote Sens. Environ., 42, 177-186, 1992.

Sevestre, H. and Benn, D. I.: Climatic and geometric controls on the global distribution of surge-type glaciers: implications for a unifying model of surging, J. Glaciol., 61, 646-662, 2015.

Sharp, M.: Surging glaciers: behaviour and mechanisms, Prog. Phys. Geog., 12, 349-370, 1988.

Wulder, M. A., Masek, J. G., Cohen, W. B., Loveland, T. R., and Woodcock, C. E.: Opening the archive: how free data has enabled the science and monitoring promise of Landsat, Remote Sens. Environ., 122, 2-10, 2012.

Yde, J. C. and Knudsen, N. T.: Glaciological features in the initial quiescent phase of Kuannersuit Glacier, Greenland, Geogr. Ann. A, 87, 473-485, 2005. 